\title{
Exploring Select U. S. Community Foundations and COVID-19 Responsive Community Philanthropy
}

\section{Patsy Kraeger ${ }^{1} \cdot$ Rhonda Phillips $^{2} \cdot$ Kerry Kuenzi $^{3} \cdot$ Imonkhae Ugboya $^{4}$}

Received: 16 December 2021 / Accepted: 21 December 2021 / Published online: 11 January 2022

(c) The Author(s), under exclusive licence to Springer Nature Switzerland AG 2021

\begin{abstract}
This article examines the extent that community foundations (CFs) are funding COVID-19 mitigation in their communities. We examine 877 of the 894 National Standards accredited community foundations in the United States for both general discretionary grantmaking to COVID-19 responsive discretionary grantmaking in a purposeful sample. Exploring the landscape of national standard certified community foundations COVID19 funding patterns in local communities presents as statistically significant. Exploratory research is presented regarding the connections between the CFs increase community well-being through early responsive discretionary grantmaking during the COVID-19 pandemic from March 2020 to midNovember 2020.
\end{abstract}

Keywords Community foundations · Community indicators · Community wellbeing · Grantmaking · National standards for U.S. community foundations · Philanthropy

\section{Introduction}

The question this study examines is: to what extent are community foundations funding COVID-19 mitigation in their communities? In order to assess the national landscape, we have used a purposeful sample of the National Standards accredited community foundations (CFs) in the United States. We compare National Standard

\section{Patsy Kraeger}

pkraeger@georgiasouthern.edu

1 Department of Public and Nonprofit Studies, Georgia Southern University, Statesboro, GA, USA

2 Purdue University, West Lafayette, IN, USA

3 Public and Environmental Affairs, University of Wisconsin Green Bay, Green Bay, WI, USA

4 Department of Public and Nonprofit Studies, Georgia Southern University, Statesboro, GA, USA 
accredited CFs general discretionary grantmaking to COVID-19 responsive discretionary grantmaking.

\section{The Study Overview}

COVID-19 has changed so many aspects of life for all including at the collective or community level. Modes of living and lifestyles have radically changed, and particularly impact those most economically vulnerable. In our study, we explore if community foundations are striving to mitigate negative impacts of the pandemic on their host communities and regions through increased funding, early in in the global pandemic. Specifically, we consider the extent of response by comparing general discretionary grantmaking to COVID-19 responsive discretionary grantmaking from 877 National Standards accredited community foundations. Despite the fact that 16 of the largest foundations in the United States are community foundations, they have not been deeply studies in the scholarly literature (Azevedo et al., 2021; Sacks, 2014).

\section{Philanthropy and Philanthropic Foundations}

Philanthropy conceptually has myriad of definitions and explanations from its ancient conceptualization to it modern meaning (Sulek, 2010a, b). Ylvisaker (1987) categorized five foundations types in the United States including "company-sponsored foundations, independent foundations, operating foundations, community foundations and public foundations" (as cited in Jung et al., 2018), p. 897. Pursuant to the 1969 Tax Reform Act, the first three are considered to be private foundations while the latter two are public charities (Jung et al., 2018). Public charities also include nonprofit organizations delivering and administering programs. A smaller portion comprises grantmaking public charities which include community foundations.

Conceptually, philanthropy's exact meaning is often contested (Daly, 2012; Sulek, 2010a, b). Expansively, philanthropy is the promotion of civil society, civic action, encouragement of volunteerism and the advancement of well-being (Sulek, $2010 a, b)$. Institutionally, philanthropy in the United States is often seen as voluntary private action for the public good (Payton, 1988). Salamon (1992) sees philanthropy as the giving of "time or valuables for public purposes... as well as a source of income for non-profit organizations" (Sulek, 2010a, p.201 citing Salamon, 1992, p.10). Building on Salamon's (1992) construct that philanthropy has a role in relation to the state. Nickel (2018) suggests scholars have presented this relationship as the logic of philanthropy (Ferris \& Williams, 2015; Hammack \& Heydemann, 2009; Mohan \& Breeze, 2016; Reich, 2016).

A broader focus than public good is that philanthropic foundations are private action for the common good or the goodness of the community in the case of place-based CFs. Nickel (2018) begins to conceptualize philanthropy as more than the state-philanthropy relationship as a primary logic. It is an interpretation of philanthropy and other logics such as well-being provide alternative interpretations that do not discount 
differing logics (Nickel, 2018). Sulek's (2010a, b) broader definition conceptualizations of modern philanthropy seem to capture the work of CFs especially with the focus on community well-being.

Kraeger and Robichau (2017) suggest that philanthropic organizations contribute to important work that solves complex problems to strengthen communities (p. 470). Ridzi (2021) suggests placed-based CFs "have long defined their value in terms of ability to improve well-being in the communities they serve" (p.1). Ridings (1997) suggest that philanthropic foundations build communities as natural convenors, drivers of community conversations and by breaking down barriers.

In this article we examine 877 of the 894 National Standard accredited Community Foundations (CFs) for both discretionary and COVID-19 grantmaking. Community foundations are grant making public charities. Graddy and Morgan (2006). We suggest that place-based discretionary and COVID-19 grantmaking CFs are: embedded in communities, representative of communities and focused on community wellbeing given these are guiding and required standards for accreditation. We also suggest that National Standard accredited Community Foundations (CFs) discretionary and COVID-19 grantmaking contributes to community well-being. We suggest thats operationalizing a community indicators 1 framework aligns with the the focused grant making of the studied National Standard accredited Community Foundations.

\section{Philanthropic Foundation Funding in the United States}

To situate the Community Foundations giving patterns in this paper, we first briefly discuss the nature, size and scope of the overall grantmaking philanthropic sector in the United States. According to Candid (2021), formerly the Foundation Center, as of 2020, there are 127,595 philanthropic foundations in the United States which include private/independent foundations, operating foundations, corporate and community foundations (Candid, 2021). Philanthropic foundation giving over time from 2014 to 2014 to 2018. In 2014, private foundation giving was 57 billion and by 2018 it was 72 billion, a 15-billion-dollar increase (Table 1).

According to Candid (2012) 2,400 funders globally awarded 68,700 recipient grants totaling $\$ 15.88$ billion dollars in the following areas: disaster relief, communicable disease control, respiratory system diseases, medical support services, emergency medical service, basic and emergency aid, community and economic development, diseases and conditions, human rights as well international development in the period from January 2020 to December 2021. Candid collecting COVID-19 funding data. Globally, the first COVID-19 grants date from January 2020 when other regions/countries were being affected before relief efforts in the United States (Candid, 2021).

\section{Community Philanthropy and Community Foundations}

Community foundations unlike other foundations are geographically placebased (Hoyt, 1996). Community Foundations are philanthropic institutions that are "embedded in place that serve donors, match them to worthwhile community 
Table 1 Global philanthropic response to coronavirus (COVID-19) ( January, 2020 to December, 2021)

\begin{tabular}{lcc}
\hline Subject & Value in Grants & Number of Grants \\
\hline Disaster relief & $\$ 10,348,084,456.00$ & 41,028 \\
Communicable disease control & $\$ 6,635,486,569.00$ & 3,818 \\
Respiratory system diseases & $\$ 5,672,124,852.00$ & 1,393 \\
Medical support services & $\$ 2,398,310,408.00$ & 6,036 \\
Emergency medical services & $\$ 1,509,117,132.00$ & 2,349 \\
Basic and emergency aid & $\$ 2,194,512,110.00$ & 14,456 \\
Community and economic development & $\$ 2,586,437,438.00$ & 3,111 \\
Diseases and conditions & $\$ 8,168,108,932.00$ & 36,030 \\
Human rights & $\$ 2,426,430,501.00$ & 5,930 \\
International development & $\$ 1,140,995,291.00$ & 217 \\
\hline
\end{tabular}

Candid (2021) Retrieved from https://topics.candid.org/issue-pages/coronavirus/funding-dashboard/\# amounts

Data Note: Funding includes awarded and announced grants between January 2020 to December 2021

projects, and make grants in a responsive manner" (Perry \& Mazany, 2015; Graddy \& Morgan, 2006 as cited in Phillips et al. (2016, p.66). Community Foundations asset sizes varies from $\$ 100,000$ to more than $\$ 1.7$ billion (Council on Foundations, 2021).

Community philanthropy differs from independent private philanthropy (both institutional and individual) in several important aspects in the United States Community philanthropy seeks to represent and respond to local community needs. Community philanthropy historically represented a broader response to community needs with the rise of national philanthropic organizations and foundations in the 1890s in the United States (Zunz, 2014; Fleishman, 2007). Community philanthropy in the United States, and later globally, institutionalized the Community Foundation as a type of organized community fund (both raising and granting funds) for community betterment. "[C]ommunity foundations serve three constituencies: charitable donors, nonprofit organizations, and the community at large (Bartenstein, 1988 as cited in Carman, 2001, p.11). As such, community foundations as trusted community partners are able to move quickly to meet local needs and work with community partners (Carman, 2001).

Community foundations are broadly understood to focus on supporting direct services nonprofit organizations and nonprofit organization capacity building to meet the community needs (Carman, 2001; Graddy \& Morgan, 2006). The discretionary funding offered by community foundations would be categorized as proactive funding proposals aligning with the community foundation's state initiative for change which are place-based (Ridzi, 2021).

Community foundations "typically are grantmakers that are highly accountable to local people, playing key roles in building trust, inclusion, and equity in communities while strengthening the capacity of civil society and building assets for the benefit of the community (Knight, 2014, p. 5). Grantmaking, then is characterized as either "proactive or responsive" (Casey, 2010, p. 21). CF giving unlike national 
funders according to Ridzi (2021) as local place-based funders with intimate community knowledge are able to "leverage local resources to address the needs" (p.2). Ridzi (2021) additionally notes that national funders tend to be focused on the specific philanthropic foundation's overall value proposition. Private foundation value proposition focus may not be focused then on the broader community. While the increase is larger in term of actual dollars the breadth may be narrower.

The Community Foundation Atlas (2020) identifies 1876 community foundations around the world, with assets of just over 5 billion or $\$ 5,028,882,755.00$. Candid, (2021) reports that there are 1184 Community Foundations in the United States with total assets of 99 billion dollars in 2020. Community Foundation giving in in 2014 was 7 billion and in 2018 it was 10 billion showing a 3-billion-dollar growth in community foundation giving CFs increased giving by $30 \%$ whereas private foundations increased giving by $20 \%$ even with the 15-billion-dollar increase shown in Table 2 below.

In 2020 as in 2019, Community Foundations granted out ten billion dollars. Candid, (2021) as shown in Table 2, below.

\section{The National Standards for U.S. Community Foundations Programs}

The Council on Foundations created National Standards to establish legal, ethical, and effective operational practices that would show community foundations' transparency and financial responsibility in the light of increased public scrutiny of foundation practices. ... The National Standards Program "represents a

Table 2 USA Philanthropic Foundation Giving Over Time

\begin{tabular}{lll}
\hline Year & Foundation Type & $\begin{array}{l}\text { Giving in } \\
\text { US\$ Bil- } \\
\text { lions }\end{array}$ \\
\hline 2018 & Private Foundations & $75 \mathrm{~B}$ \\
2018 & Community Foundations & $10 \mathrm{~B}$ \\
2017 & Private Foundations & $72 \mathrm{~B}$ \\
2017 & Community Foundations & $10 \mathrm{~B}$ \\
2016 & Private Foundations & $66 \mathrm{~B}$ \\
2016 & Community Foundations & $8 \mathrm{~B}$ \\
2015 & Private Foundations & $61 \mathrm{~B}$ \\
2015 & Community Foundations & $7 \mathrm{~B}$ \\
2014 & Private Foundations & $57 \mathrm{~B}$ \\
2014 & Community Foundations & $7 \mathrm{~B}$ \\
\hline
\end{tabular}

(Candid, 2021)

Data Note: Based on a historical view of the IRS Business Master File (BMF) for the given fiscal year end. Limited to organizations with a filing address in the 50 U.S. states and D.C. Based on the most recent IRS filing, 2015 or later, available for organizations appearing in the December 2020 IRS BMF 
community foundation's commitment ... to demonstrate accountability and excellence to communities, policymakers, and the public" (National Standards for U. S. Community Foundations, 2020).

The National Standards accredited community foundations (CFs) comprise $96 \%$ of the largest community foundations in the United States (National Standards for U.S. Community Foundations, 2020). These standards are evidence that community foundations "establish legal, ethical, and effective operational practices that would show community foundations' transparency and financial responsibility in light of increased public scrutiny of foundation practices" (National Standards for U.S. Community Foundations, 2020).

The baseline criterion is that the organization must be a tax-exempt organization pursuant to the Internal Revenue Code sections 501(c)(3), 509(a)(1), and 170(b)(1) (a)(vi), (2020) as well as other required and relevant federal and state regulations (National Standards for U.S. Community Foundations, 2020). The self-described focus is "operational effectiveness to foster excellence in community philanthropy" (National Standards for U.S. Community Foundations, 2020). Excellence is achieved through "operationally and legally sound community foundations" and training on the standards and the processes related to the standards allowing for "confidence in CF operation" (National Standards for U.S. Community Foundations, 2020).

The National Standards for U.S. Community Foundations accreditation program creates a network of community foundations that share a similar goal to maximize organizational effectiveness (National Standards for U.S. Community Foundations, 2020). There are 26 standards focusing on five core areas: 1) mission, structure \& governance; 2) resource development; 3) stewardship \& accountability; 4) grantmaking; and 5) donor relations (National Standards for U.S. Community Foundations, 2020). CFs in order to be accredited must meet all 26 standards (National Standards for U.S. Community Foundations, 2014, p. 1).

More than creating a network of organizations with shared goals. The standards allow for organizational accountability in all five key areas. Day and Klein (1987) suggest that "[a]accountability then, is about the construction of a grammar of conduct and performance and the standards used to assess them" (Molnár, 2008, p.129). Grammar, defined refers to the system and structure of languages as prescribed by rules (Grammar (2021) in the Oxford English Dictionary, 2021). Likewise, these 26 community foundation national standards, in turn, are the system and structure of rules that accredited CFs agree to uphold in order to improve "evidence of excellence; accountability; impact: and distinction" (National Standards for U.S. Community Foundations, 2014, p. 1).

Within the 26 standards, there are three grantmaking standards, 18, 19 and 20. Standard 19 is central to this study as we are focused on the actual grantmaking activities of the CF. CF must "award some grants from its discretionary resources" (National Standards for Community Foundations, 2014, p. 4). Standard 18 requires CFS to offer a broad grantmaking program and to make sure funding guidelines, a list of past grantees is available, award letters are generated along with the grantee use compliance (National Standards for Community Foundations, 2020). Standard 20 requires that $\mathrm{CFs}$ "performs due diligence to ensure that grants will be used for charitable purposes and assesses the impact of its grantmaking" (National Standards for Community Foundations, 2020). 
We did not focus on standards 18 and 20 for this study given that grant-making foundations including CFs provided more flexible funding with simpler and streamlined processes for accessing the funding (Orensten et al., 2020). Standard 19 allows us to explore the grantmaking initiatives of the accredited CFs.

\section{Measuring Community Change}

Changes over time in communities can be measured by a variety of methods and approaches. Some use indicators, as explained in the next section, while others gauge impacts of changes via observation of trends or behaviors. For example, healthy community projects attempt to cultivate a "sense of shared responsibility for community health and well-being" (Besleme \& Mullin, 1997, p. 43); this in turn influences health outcomes for residents. Some community foundations might focus on a particular aspect such as the deployment of financial capital increase community health and well-being.

Exploring community foundation grantmaking provides insight into inherent strengths and opportunities as well as areas for improvement and mitigation. Grantmaking mapping can provide valuable data supporting community foundation's mission, goals and benchmarks for community well-being through funding. Community foundations, as well as those involved with community development of an area, find these useful for many reasons, not the least of which is to better connect need with funding to aid in change management.

\section{The Use of Community Indicators to Measuring Community Well-Being and Change Initiatives}

Community foundations will find use of indicators valuable to aid their efforts to better understand conditions over time in their funding areas. Community indicators are measures tracking progress in local systems. They provide insight into the overall direction of a community: whether it is improving, declining, or staying the same, or is some mix of all three (Andrews, 2001; Choi et al. 2020; Phillips, 2003; Phillips \& Wong, 2017; Sung \& Phillips, 2016, 2018). The strength of a community indicators measuring system lies in the involvement of citizens, residents and stakeholders; citizen (or resident and stakeholder) participation can itself be treated as an indicator (Phillips, 2003; Sung \& Phillips, 2016, 2018).

Community indicators, particularly when used as a system for larger, more comprehensive understanding of an area, can provide data for subsequent decisionmaking by those in the community or foundations (Andrews, 2001; Phillips, 2003; Sung \& Phillips, 2016, 2018). Indicators can be used to assess a wide range of data, from specific objective indicators (population changes, health by age cohorts, per capita and household incomes) to subjective type indicators (those that reflect perceptions or preferences such as satisfaction). Indicator systems can also help further understanding of related dimensions important to communities, and thus by default, can be of interest to community foundations (Andrews, 2001; Ridzi, 2021; Phillips, 
2003; Sung \& Phillips, 2016, 2018). These includes allied concepts of community development which are essentially efforts to improve or make progress in an area by building capacity for achieving desirable outcomes by and for those who live there (Phillips \& Pittman, 2015).

\section{Types and Scale of Community Indicators: Systems and Performance Indicators}

There are two basic, very similar types of indicators: system indicators (sometimes called descriptive) and performance indicators (can be used to gauge outcomes). System indicators summarize individual measurements that describe multiple characteristics of a specific system-an ecosystem, for example, or a social system and communicate the most relevant information to decision makers (Hardi et al., 1997; Phillips, 2003; Phillips \& Wong, 2017; Sung \& Phillips, 2016, 2018). Performance indicators are similar to system indicators in that both are descriptive-they describe a particular system (Phillips, 2003). Performance indicators are also prescriptive: They include a reference value or policy target that allows comparisons with local, national, or international goals, targets, and objectives (Phillips, 2003). Performance indicators are particularly useful in the policy evaluation phase of the decision-making process (Hardi et al., p. 9). Performance indicators are used in the context of organizational or community goal setting (Phillips, 2003).

In this study we use and operationalize select National Standards for Community Foundations as performance indicators to examine grantmaking efforts. The National Standards accreditation program prioritizes discretionary grantmaking in its standard 19 which states that grantmaking meets community needs while emphasizing both robust dissemination of opportunities in the community and the need for evaluation of the grantmaking. Examining the discretionary grantmaking opportunities across the National Standard CFs examining both financial capital and responsive mitigation indicators provides insight into community foundations funding priorities early in the pandemic.

\section{Financial Capital as a Community Indicator}

Financial capital is one component of Emery \& Flora (2005) and Flora and Flora's (2013) community capital analysis. Financial capital "includes the financial resources available to invest in community capacity building, underwrite businesses development, support civic and social entrepreneurship, and accumulate wealth for future community development" (Flora \& Flora, 2013). Social capital (active connections among people) is central to financial capital because it includes access to credit markets and funding sources (Haines, 2015). This indicator is solidly used and reflective of community development scholarly and practice approaches; at the same time, it can be seen as connecting and influencing other related dimensions such as community well-being (more financial resources may enable more residents to participate in economic development, for example) as well as quality of life (e.g., 
stable or expanding income sources as enabled by financial capital would positively impact quality of life). For these reasons, financial capital is selected as a representative indicator for inclusion in our study, given its propensity to favorably impact community outcomes.

\section{Community Mitigation Strategy Response Indicators}

The Centers for Disease Control recognizes that response needs to be both from a medical and a public health perspective but also to incorporate community determinants of health including the commitment of organization to build community capacity in order to mitigate the impacts of the COVID-19 pandemic disaster.

Specifically, the CDC wants to understand "which community mitigation strategies do jurisdictions implement, and how and when are they implemented" (Centers for Disease Control, 2020)? One indicator of community mitigation is the number of Community- and Faith-Based Organizations or local leaders who are engaged to implement COVID-19 community-level mitigation strategies. We suggest that before examining the number of direct service providers, it is important to understand the extent to which community foundations as community-led philanthropic organizations are funding COVID-19 mitigation. This is why we combine the use of Flora and Flora's (2013) financial capital element with the CDC COVID-19 Mitigation Indicator as adapted, in this study to measure community foundation COVID19 responsive discretionary grantmaking.

\section{Types of Grantmaking, Discretionary Funding and Discretionary COVID-19 Funding}

The majority of the community foundations that are national standards accredited are involved in place-based discretionary grantmaking on a regular basis (Mack et al. 2014. Of the 894 national standards accredited organizations, 877 are community foundations. These 877 are in our purposive sample. Other organizations include business, corporations, law firms or a stand-alone donor advised fund (DAF).

Grantmaking community foundations that do not offer competitive discretionary grants are typically limited to community scholarships and tend to be smaller in both asset and giving size. In general, annual discretionary funding offered in 2020 is also an example of proactive grantmaking by community foundations is robust. This grantmaking continued to assist with the impacts of COVID-19 in addition to regular community foundation grantmaking for National Standards accredited foundations.

According to Candid (2020) and the Center for Disaster Philanthropy (2020) community foundations awarded more grants than any other type of grantmaker. Currently, community foundations as a whole awarded 49 percent of total awards as of July 2020 as shown in Tables 3, 4, and 5.

Corporate Foundations awarded 11 percent of total awards as of July 2020 or just 487 total gifts. It is notable that the amount of the funding was just under eight 
billion dollars, many times greater that of community foundations listed in Table 5. Table 4 in the following lists corporate foundations' giving.

Private foundations gave about a fourth of what corporate foundations gave or $16 \%$ of total dollars through July 2020 compared to the $49 \%$ of gifts from community foundations and $14 \%$ from corporate foundations. As a general rule, we can see that community foundations gave far away a greater number of grants which suggests that communities recognized local needs through gift giving but in terms of total amount of giving, both corporate and private foundations gave far more in fewer numbers of grants. Table 5 below shows giving by private foundations.

Noting the responsiveness of place-based community foundations to quickly respond to local needs, preliminary categorical data was examined to assess the likelihood of community foundations to respond quickly and separately from general discretionary funding. Community foundation's immediate crisis response is an important first step towards building community well-being.

\section{Study Approach, Methods, Data Collection and Results}

To identify the extent that community foundations (CFs) are funding COVID-19 mitigation in their communities, we collected data from 877 of the 894 accredited National Standard Community Foundation organizations in a purposeful sample. Purposeful samples are nonprobability samples, both data rich and often criterion based for phenomenon of interest. (Palinkas et al., 2015).

Data were collected by examining each foundation's websites and more general internet searches (when information was not available on their personal websites) were used to examine their patterns of discretionary grant making and COVID-19

Table 3 COVID-19 Mitigation Grants: Comparisons by the Number for Community Foundations
$1 \%$ of total philanthropic dollars for COVID-19 mitigation/response funding

$\$ 136,799,844$ (in Millions) as of July 2020

$49 \%$ or 4097 total grants/gifts as of July 2020

Candid (2020); Center for Disaster Philanthropy (2020)
Table 4 COVID-19 Mitigation/ Response Grants: Comparisons by the Numbers: Corporate Foundations
$66 \%$ of total philanthropic Dollars for COVID-19 mitigation/ response funding

$\$ 7,855,545,271$ (in Billions) as of July 2020

$11 \%$ or 487 total grants/gifts as of July 2020

Candid (2020); Center for Disaster Philanthropy (2020)

$14 \%$ of total philanthropic Dollars for COVID-19

$\$ 1,702,077,356$ (in Billions) as of July 2020

$16 \%$ or 1611 total grants/ gifts as of July 2020

Candid (2020); Center for Disaster Philanthropy (2020)
Table 5 COVID-19 Mitigation/ Response Grants: Comparisons by the Numbers: Private Foundations 
funding as well as fund-raising activities to support grantmaking efforts. Finally, of the 894 community foundations, we were unable to identify whether 23 of these organizations offered either discretionary community grants or COVID-19 funding so these were coded as missing and excluded from analysis.

\section{Measures}

Grant-making in this study is the criterion we are examining. Community foundations that self-select into the National Standards Program have increased odds of community grant-making and thus represent a purposeful sample to investigate differences in funding during the pandemic. More specifically, this study investigates two types of grant making. The first category whether the foundation meets Community Foundation National Standard 19 broad discretionary proactive grantmaking. We also measure whether the foundation responded to the call by the CDC for COVID-19 response measures. For each community foundation, we identified if they offered either type of funding and coded as a 1 or 0 (yes, no). For analysis, we recoded the variable to reflect whether the organization offered either type of funding alone, neither, or both with Table 5 below summarizing the number and percentage of each.

\section{Hypothesis Testing}

The relationship between community financial capital and disaster mitigation is examined through community foundation discretionary and COVID-19 responsive grantmaking activity in our sample in the early stages of the global pandemic in the United States by testing the following hypothesis that predict two patterns of funding present for mitigating the impact of COVID-19 using a one-sample $t$ test for proportions.

While the funding patterns are fairly clear from the summary statistics already, a parametric test such as this allows us whether to identify these differences are statistically significant. The one-sample $t$ test allows us to identify the proportion of foundations that are statistically different within the sample against a predicted value. In this case, it allows us to statistically identify whether the proportion of organizations offering different types of funding (both in $\mathrm{H}_{1}$ and discretionary in $\mathrm{H}_{2}$ ) is statistically different.

$\mathrm{H}_{1}$ : Community foundations accredited by the National Standards Accredited program will offer both discretionary funding and COVID-19 response funding. $\mathrm{H}_{2}$ : Community foundations accredited by the National Standards Accredited program that do not offer both types of funding are more likely to offer discretionary funding response funding than COVID-19. 


\section{Analysis and Results}

We suggest that accredited CFs that meet the national standards provide some evidence of confidence that these CFs are being responsive to community needs as indicated by standard 19, by providing discretionary grants respond to community needs. Discretionary grants are from the community foundation's discretionary funds not its Donor Advised Funds. In this time of the global pandemic, we wanted to examine, how likely the CFs were to engage in expanded COVID-19 funding in addition to discretionary grant-funding.

Table 6 presents the results of our one sample $t$-test a demonstrating a clear pattern of funding. As expected, hypothesis 1 is confirmed since the National Standard accredited Community Foundations are more likely to be involved and fund in broad range of discretionary grantmaking given the self-selection to be accredited. What was unknown was the likelihood of these foundations to engage in further responsive COVID-19 grantmaking in the pandemic's early stage.

Table 7 presents the results from the one-sample $t$ test analysis for National Standard accredited Foundations Discretionary and COVID-19 funding activity to verify the differences in funding was statistically significant. The results from testing the hypotheses are found in Table 7.

The results confirmed that of the community foundations offering funding, the number of organizations offering both types of funding are statistically significant ( $t=45.529, d f=871, p<0.001)$, confirming the first hypothesis. Of the organizations that offered one type of funding or the other $(n=112)$, we again see a statistically significant difference $(t=111.00, d f=111, p<0.001)$, confirming the second hypothesis.

The results show that a statistically significant number of the 877 National Standard Accredited Community Foundations in this study were able to move quickly between March 2020 and November 2020 to provide additional responsive COVID-19 disaster relief funding beyond the ongoing discretionary grantmaking cycle of 2020 in place prior to the onset of the pandemic. We have examined activity not actual grant amount or duration in this study. That said, the results of the increased activity examined from a review of websites seems to be consistent with the role of community foundations as responsive change agents in local communities. Additionally, this data seems to be consistent with Besleme and Mullin's (1973) observation that healthy community projects attempt to cultivate a "sense of shared responsibility for community health and well-being" (p.43).

\section{Conclusion}

The data show that community foundations are key partners for communities seeking to mitigate the negative impacts of COVID-19 on local communities through discretionary grantmaking. Emery and Flora (2006) as well as the Centers for Disease Control COVID-19 mitigation recognize the need for community 


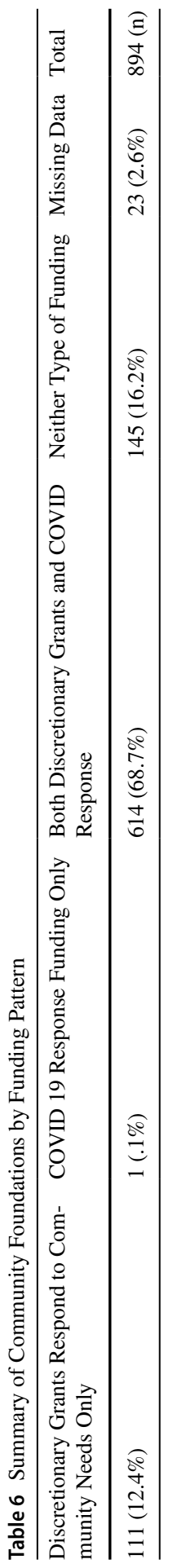


Table 7 One-Way Sample $t$ test for National Standard Certified Foundations Discretionary and COVID19 Funding

\begin{tabular}{|c|c|c|c|c|c|c|c|c|}
\hline & $\mathrm{n}$ & mean & Std. Deviation & Std. Error Mean & Test Value & $\mathrm{t}$ & df & Sig \\
\hline H 1 & 726 & .70 & .457 & .015 & 0 & 45.529 & 871 & .000 \\
\hline H 2 & 112 & .99 & .094 & .009 & 0 & 111.00 & 111 & .000 \\
\hline
\end{tabular}

led responses as part of a sustainable solution to the path back after the COVID19 crisis.

Those community foundations prioritizing community responsiveness, measuring accountability and engaging in broad discretionary proactive grantmaking are more likely to engage in grantmaking for community change. Recognizing financial capital as it connects to COVID -19 mitigation in communities is a broad effort. Using the rationales from Emery and Flora's (2003) further refined in Flora and Flora's (2013) financial capital indicator from the Community Capitals framework coupled with and the Centers for Disease Control indicator for COVID-19 mitigation aligns with the rationale for National Standards 19. Standard 19 focuses on the need for dissemination of the grantmaking opportunities to nonprofits and others qualifying in communities. Thus, we have focuses on grantmaking activity in this paper.

Exploring National Standards Community Foundations discretionary and COVID-19 responsive grantmaking activity is important to understand in relation to community well -being. These organizations are committed to being part of a larger structure. A system that is committed to having community impact, achieving excellence through place-based engagement and being accountability to mission as well as community well-being. Exploring how these organizations are building community capacity with ongoing financial capital and fundraising to support these initiatives helps scholars and practitioners see the breadth and depth of community financing initiatives. Community foundations are critical entities positioned to benefit a community through enhanced quality of life, improved community well-being and strong capacity for local problem-solving to respond and mitigate the impacts of COVID-19 in local communities. Our work seeks to help bridge the gap between the study of community philanthropy and community well-being and quality of life as being responsive to communities in COVID-19.

The COVID-19 pandemic crisis as of the date on publication is still ongoing. National Standard accredited Community Foundations are still partnering with communities for impact as well as increased well-being. This initial exploration allows us to build on the scholarly and practitioner literature examining not only assessing grant-making but to re-focus community-centric philanthropy from a well-being perspective to expand the literature in this field beyond crisis grant-making.

Author Contributions Patsy Kraeger and Rhonda Phillips contributed to the study conception and design. Material preparation and data collection were performed by Patsy Kraeger and Data collection only by Imonkhae Ugboya. Statistical analysis was performed by Kerry Kuenzi. The first draft of the manuscript 
was written by Patsy Kraeger and co- authors Phillips and Kuenzi commented on previous versions of the manuscript. Authors Kraeger, Phillips and Kuenzi read and approved the final manuscript.

\section{Declarations}

Conflict of Interest On behalf of all authors, the corresponding author states that there is no conflict of interest.

Competing Interests The authors have no relevant financial or non-financial interests to disclose.

\section{References}

Andrews, C. J. (2001). Analyzing quality-of-place. Environment and Planning B: Planning and Design, 28(2), 201-217.

Azevedo, L., Bell, A., \& Medina, P. (2021). Community foundations provide collaborative responses and local leadership in midst of COVID-19. Nonprofit Management and Leadership, 1-11.https://doi. org/10.1002/nml.21490

Bartenstein, F. (1988). What is a community foundation, anyway? Point of View Series. Council on Foundations.

Besleme, K., \& Mullin, M. (1997). Community indicators and healthy communities. National Civic Review, 86(1), 43-52.

Candid (2012). Philanthropic response to coronavirus (COVID-19). Retrieved on December 13, 2021 from https://topics.candid.org/issue-pages/coronavirus/funding-dashboard/\#amounts

Candid (2020). Key facts on U.S. nonprofits and foundations. Retrieved on June 1, 2020, from https:// candid.issuelab.org/resource/key-facts-on-u-s-nonprofits-and-foundations.html

Candid (2021). Key facts on U.S. nonprofits and foundations. Retrieved on December 13, 2021 from https://candid.issuelab.org/resource/key-facts-on-u-s-nonprofits-and-foundations-2021.html

Carman, J. G. (2001). Community foundations: A growing resource for community development. Nonprofit Management and Leadership, 12(1), 7-24.

Casey, J. (2010). Mapping in philanthropy: Exploring the use of mapping in foundation grantmaking.

Centers for Disease Control. (2020) An approach for monitoring and evaluating community mitigation strategies for COVID-19. Retrieved October 1, 2020, from https://www.cdc.gov/coronavirus/2019ncov/php/monitoring-evaluating-community-mitigation-strategies.html

Center for Disaster Philanthropy (2020). Philanthropy and COVID-19 in 2020: Measuring one year of giving. Retrieved on December 1, 2021, from https://disasterphilanthropy.org/resources-2/phila nthropy-and-covid-19/

Choi, N., Kim, J., \& Lee, S. J. (2020). The usefulness of intersubjective community wellbeing as a community development indicator: Evidence from comparing three approaches to measuring community wellbeing. International Journal of Community Well-Being, 3, 173-192. https://doi.org/10. 1007/s42413-020-00059-6

Community Foundation Atlas. (n.d.). Facts. Retrieved December 10, 2020, from https://communityf oundationatlas.org/facts/

Council on Foundations (2021). Community foundations. Retrieved October 21, 2021, from https://www. cof.org/foundation-type/community-foundations-taxonomy

Daly, S. (2012). Philanthropy as an essentially contested concept. Voluntas: International Journal of Voluntary and Nonprofit Organizations, 23(3), 535-557.

Day, P., \& Klein, R. (1987). Accountabilities: Five public services. Tavistock.

Emery, M., \& Flora, C. B. (2006). Spiraling-up: Mapping community transformation with community capitals framework. Community Development: Journal of the CommunityDevelopment Society, $37(1), 19-35$.

Ferris, J. M., \& Williams, N. P. O. (2015) Philanthropy and government working together: The role of offices of strategic partnerships in public problem solving. The Center on Philanthropy \& Public Policy, University of Southern California. Retrieved December 13, 202, from http://cppp.usc.edu/ wp-content/uploads/2012/11/WorkingTogether_final.pdf. 
Fleishman, J. L. (2007). The foundation: A great American secret; how private wealth is changing the world. Public Affairs.

Flora, C. B., \& Flora, J. L. (2013). Rural communities: Legacy and change (4th ed.). Westview Press.

Graddy, E. A., \& Morgan, D. L. (2006). Community foundations, organizational strategy, and public policy. Nonprofit and Voluntary Sector Quarterly, 35(4), 605-630.

Grammar. (2021). In Oxford English dictionary. Retrieved December 14, 2021, from https://www.oed. $\mathrm{com} /$ view/Entry/80574?result=1\&rskey $=\mathrm{J} 3 \mathrm{LZpI} \&$

Haines, A. (2015). Asset-based community development. In R. Phillips \& R. Pittman (Eds.), Introduction to community development (2nd ed., pp. 45-56). Routledge.

Hammack, D. C., \& Heydemann, S. (2009). Philanthropic projections: Sending institutional logics abroad. In D. C. Hammack \& S. Heydemann (Eds.), Globalization, philanthropy, and civil society: Projecting institutional logics abroad (pp. 3-31). Indiana University Press.

Hardi, P., Barg, S., Hodge, T., \& Pinter, L. (1997). Measuring sustainable development: Review of current practice. Occasional Paper Number 17, pp. 1-123. Industry Canada. Retrieved October 15, 2020 from https://www.ic.gc.ca/eic/site/eas-aes.nsf/vwapj/op17e.pdf/\$file/op17e.pdf

Hoyt, C. J. (1996) Legal compendium for community foundations. Council on Foundations.

Internal Revenue Code sections 501(c)(3), 509(a)(1), and 170(b)(1)(a)(vi) (2020)

Jung, T., Harrow, J., \& Leat, D. (2018). Mapping philanthropic foundations' characteristics: Towards an international integrative framework of foundation types. Nonprofit and Voluntary Sector Quarterly, 47(5), 893-917.

Knight, B. (2014). Dimensions of the field: An in-depth analysis of the community foundation movement. Retrieved October 15, 2020 from www.communityfoundationatlas.org

Kraeger, P., \& Robichau, R. (2017). Questioning stakeholder legitimacy: A philanthropic accountability model. Journal of Health and Human Services Administration, 470-519.

Mack, K., Preskill, H., Keddy, J., \& Jhawar, M. M. K. (2014). Redefining expectations for place-based philanthropy. The Foundation Review, 6(4), 30-43.

Molnár, M. (2008). The accountability paradigm: Standards of excellence: Theory and research evidence from Hungary. Public Management Review, 10(1), 127-137.

Mohan, J., \& Breeze, B. (2016). The logic of charity: Great expectations in hard times. Palgrave MacMillan.

National Standards for U.S. Community Foundations. (2014). Retrieved on March 1, 2020 from https:// www.cfstandards.org/getting-accredited/national-standards.

National Standards for U.S. Community Foundations. (2020). Retrieved on March 1, 2020 from https:// www.cfstandards.org.

Nickel, P. M. (2018). Philanthropy and the politics of well-being. PS: Political Science \& Politics, 51(1), 61-66.

Orensten, N., Buteau, E., Gehling, K., Malmgren, K., Marotta, S., \& Martin, H. (2020). Foundations respond to crisis. Center for Effective Philanthropy.

Palinkas, L. A., Horwitz, S. M., Green, C. A., Wisdom, J. P., Duan, N., \& Hoagwood, K. (2015). Purposeful sampling for qualitative data collection and analysis in mixed method implementation research. Administration and Policy in Mental Health, 42(5), 533-544. https://doi.org/10.1007/ s10488-013-0528-y

Payton, R. L. (1988). Philanthropy: Voluntary action for the public good. Greenwood.

Perry, D. C., \& Mazany, T. (2015). The second century: Community foundations as foundations of community. In T. Mazany \& D. C. Perry (Eds.), Here for good: Community foundations and the challenges of the 21 st century (pp. 3-26). Routledge.

Phillips, R. (2003). Community indicators. American Planning Association.

Phillips, R., \& Pittman, R. (2015). An introduction to community development (2nd ed.). Routledge.

Phillips, R., \& Wong, C. (2017). Handbook of community well-being research. Springer.

Phillips, S., Bird, I., Carlton, L., \& Rose, L. (2016). Knowledge as leadership, belonging as community: How Canadian community foundations are using vital signs for social change. The Foundation Review, 8(3), 66-80. https://doi.org/10.9707/1944-5660.1314

Reich, R. (2016). Repugnant to the whole idea of democracy? On the role of foundations in democratic societies politics. PS: Political Science and Politics (July), 466-471.

Ridings, D. S. (1997). Philanthropy in action: Building community. National Civic Review, 86(4), 281-287.

Ridzi, F. (2021). Place-based philanthropy and measuring community well being in the age of COVID19. International Journal of Community Well-Being, 1-19. 
Sacks, E. (2014). The growing importance of community foundations.

Salamon, L. M. (1992). America's nonprofit sector: A primer. Foundation Center.

Sulek, M. (2010a). On the modern meaning of philanthropy. Nonprofit and Voluntary Sector Quarterly, 39(2), 193-212.

Sulek, M. (2010b). On the classical meaning of philanthrôpía. Nonprofit and Voluntary Sector Quarterly, 39(3), 385-408.

Sung, H., \& Phillips, R. (2016). Conceptualizing a community well-being and theory construct. In S. J. Lee, Y. Kim, \& R. Phillips (Eds.), Social factors and community well-being. Springer.

Sung, H., \& Phillips, R. G. (2018). Indicators and community well-being: Exploring a relational framework. International Journal of Community Well-Being, 1(1), 63-79.

Ylvisaker, P. N. (1987). Foundations and nonprofit organizations. In W. W. Powell (Ed.), The nonprofit sector: A research handbook (pp. 360-379). Yale University Press.

Zunz, O. (2014). Philanthropy in America. Princeton University Press.

Publisher's Note Springer Nature remains neutral with regard to jurisdictional claims in published maps and institutional affiliations. 